\title{
Article \\ Recurring Cystitis: How Can We Do Our Best to Help Patients Help Themselves?
}

\author{
Sarah Ben Hadj Messaoud, Elisa Demonchy and Véronique Mondain *
}

check for updates

Citation: Ben Hadj Messaoud, S.; Demonchy, E.; Mondain, V. Recurring Cystitis: How Can We Do Our Best to Help Patients Help Themselves? Antibiotics 2022, 11, 269. https:// doi.org/10.3390/antibiotics11020269 Academic Editors: Barbara Kot and Piotr Szweda

Received: 28 December 2021 Accepted: 16 February 2022 Published: 18 February 2022

Publisher's Note: MDPI stays neutral with regard to jurisdictional claims in published maps and institutional affiliations.

Copyright: (C) 2022 by the authors. Licensee MDPI, Basel, Switzerland. This article is an open access article distributed under the terms and conditions of the Creative Commons Attribution (CC BY) license (https:// creativecommons.org/licenses/by/ $4.0 /)$.
Infectious Diseases Department, Université Côte d'Azur, Centre Hospitalier Universitaire de Nice, 06000 Nice, France; sarah.benhadjm@gmail.com (S.B.H.M.); demonchy.e@chu-nice.fr (E.D.)

* Correspondence: mondain.v@chu-nice.fr

\begin{abstract}
Recurrent cystitis (RC) has rarely been studied; its management varies and research on a holistic approach of these patients is scarce. We attempted to characterize patients suffering from $\mathrm{RC}$ and investigated their current care pathways, aiming to offer customized and autonomous management. In this paper, we present a descriptive, single-center, cross-sectional study of women presenting with RC at an infectious disease (ID) clinic. A questionnaire was developed and was completed by ID physicians during patient visits. From October 2016 to January 2019, 202 women were included (mean age 59 years). Sexual intercourse, stress and diarrhoea/digestive symptoms were reported as trigger factors by $35 \%, 34 \%$ and $19 \%$ of patients, respectively. A majority (54\%) were at risk for complications and were those more exposed to inappropriate antibiotic prescriptions. In total, $56 \%$ of women suffered from more than 10 episodes/year and $48 \%$ suffered from relapses, mainly due to E. coli. Genitourinary syndrome of menopause (GSM) was a frequent complaint (74.5\% of women). Fluoroquinolones and 3rd generation cephalosporins were prescribed in $38 \%$ and $30 \%$ of women, respectively. Most women wished for non-antimicrobial approaches and autonomy. Patients require comprehensive, tailored care in order to benefit from a broader range of treatment options in compliance with recommendations.
\end{abstract}

Keywords: recurrent cystitis; urinary tract infection; antibiotic prescription; non-antibiotic treatment

\section{Introduction}

In France, in 2016, urinary tract infections (UTI) were estimated to account for a third of all antibiotic prescriptions, most of which were provided by general practitioners (GP) [1] That year, the societal cost of UTI in France was estimated at €58 million, of which $25 \%$ were associated with negative cultures [2].

In the USA, the prevalence rate for these infections in women is over $50 \%$, with approximately 3\% developing recurring cystitis (RC), i.e., at least four episodes a year [3].

To our knowledge, research on RC in France has, until now, been limited. A study conducted in 2006 concluded that $2.3 \%$ to $10 \%$ of women suffered from this condition, but little is known of patients at risk for complications, and no specific recommendations have been published for these patients [4].

Management of RC is highly variable both within and between countries [5]. Case definition and diagnosis are not clear-cut, as clinical and biological factors and/or overall risk factors are not considered. This results in a monolithic approach involving iterative antibiotic treatment courses, leading to emergence of antimicrobial-resistant bacteria and significant side-effects [6]. Women in many countries appear unhappy with the way RC is managed [7].

The French language infectious disease society (Société de Pathologie Infectieuse de Langue Française, SPILF) updated its recommendations in 2015 and 2017, excluding the use of third-generation cephalosporins (3GC), amoxicillin-clavulanate combinations, and fluoroquinolones for the management of uncomplicated acute cystitis and those at 
risk of complications [8,9]. However, compliance with recommendations is inadequate; antibiotic prescription remains inappropriate, with persistent use of critically important compounds [10].

Most scientific research on RC has focused on pathological processes, antimicrobial treatment and its alternatives, antibacterial resistance and inappropriate antibiotic use. However, patients' behavioural and psychological determinants have not been extensively explored. Although cystitis is considered a mild condition that can cure spontaneously in $40 \%$ of cases when uncomplicated [11], it exerts a major impact on women's quality of life [12]. Little is known about the use of health care services by these patients, while consequences for society are significant [2].

To investigate and improve practices, a working group was established within the PACA-Est Infectious Disease network.

The present study, thus, aimed to identify these patients' profiles and to describe their care pathways as a preliminary step, prior to suggesting a customized management strategy to be subsequently assessed.

\section{Method}

This was a single-centre cross-sectional study conducted on patients who presented with recurrent cystitis at the infectious diseases department outpatient clinic of Nice University Hospital between 19 October 2016 and 15 January 2019.

\subsection{Study Population}

Female patients with $\mathrm{RC}$ who presented at the infectious disease outpatient department of Nice University Hospital were recruited.

\subsection{Data Collection}

A questionnaire was developed, (See Supplementary Material File) based on the SPILF recommendations and the propositions put forward by the working group and was validated by the PACA-Est Infectious Diseases Network, comprising GPs, infectious disease specialists (ID), urologists, gynaecologists, pharmacists and biologists.

The questionnaire was given to the patient as she arrived at the outpatient clinic, allowing her the time to reflect on the questions relating to RC. It was then completed with the 2 ID specialists who were consulted by these women. The resulting database included study population characteristics: age group, socio-professional category, perceived psychological profile, patient history (age of onset of cystitis, circumstances of occurrence, trigger factors, complications), clinical signs, risk factors (family history, risk behaviour, hormonal status), risk factors for complications, and bacterial ecology within the cohort.

The questionnaire also explored ambulatory care pathways: management, investigation procedures and treatment of RC.

Ethical approval was not required for this study, as it was an internal single-centre institutional research project in line with the general information provided to all patients on data utilisation. A standard institutional document explaining this use is systematically signed by patients visiting the institution. The study has been entered in the institutional register of data processing activity under number 2022033CHUN.

\subsection{Statistical Analysis}

Data were entered and analysed, and graphs constructed using MS Excel software. Descriptive statistical analysis was performed with variables shown as $\mathrm{N}$ and $\%$.

\subsection{Results}

Two hundred and two patients were recruited between 19 October 2016 and 15 January 2019. The first 54 patients completed the questionnaire with the ID specialist during the consultation, as it was still not available as a hand-out. The remaining 148 questionnaires 
had been given to the patients just before the consultation, thus, allowing time for them to read and reflect upon the questions before discussing them with the ID specialist.

Mean patients' age was 59 years (range: 17 to 90 years), 71\% were over 50, 58\% were retired and $79 \%$ were urban residents, $74.5 \%$ were in perimenopause or menopause. Symptomatic anxiety was described by $62 \%$ of patients, $7 \%$ of whom stated that they were depressed. Most women had at least one child, while $26 \%$ were nulliparous.

A majority $(62.5 \%)$ of women described a history of cystitis of at least ten years' duration, dating back to childhood for $12 \%$ of them. Frequency of cystitis had increased over the past three years for $55 \%$ of patients; $43 \%$ stated that this had been the case since menopause. Over half the patients (55\%) had more than 10 episodes of cystitis every year. The main trigger factors included sexual intercourse (36\%) and stress (35\%), followed by diarrhoea (19\%). Forty percent mentioned a history of acute pyelonephritis. Clinical signs reported by patients included urinary frequency $(72 \%)$, burning sensation upon micturition $(70 \%)$, suprapubic pain $(65 \%)$, smelly urine $(22 \%)$ urinary incontinence $(18 \%)$, hematuria $(17 \%)$ and cloudy urine $(14 \%)$.

Risk factors for an episode of cystitis are described in Table 1, while those for complications are shown in Table 2.

Table 1. Factors identified as favouring cystitis when questioning patients.

\begin{tabular}{|c|c|c|}
\hline Favouring Factors & $\mathbf{N}$ & $\%$ \\
\hline \multicolumn{3}{|l|}{ Trigger Factors: } \\
\hline Sexual intercourse & 73 & $36 \%$ \\
\hline Stress & 71 & $35 \%$ \\
\hline Diarrhoea & 38 & $19 \%$ \\
\hline \multicolumn{3}{|l|}{ Behavioural factors } \\
\hline Anxiety & 125 & $62 \%$ \\
\hline Hydration $<1.5 \mathrm{~L} /$ day & 65 & $32 \%$ \\
\hline \multicolumn{3}{|l|}{ Bladder irritants: } \\
\hline Excess intake of tea, coffee, alcohol & 38 & $19 \%$ \\
\hline Tobacco & 25 & $13 \%$ \\
\hline Withheld or non-seated micturition & 55 & $28.5 \%$ \\
\hline Excessive intimate hygiene $\geq 2 x /$ day & 78 & $40.5 \%$ \\
\hline Inadequate drying & 5 & $2.5 \%$ \\
\hline Aggravating sports (cycling, horse-riding ... ) & 16 & $9 \%$ \\
\hline Obesity & 23 & $12 \%$ \\
\hline \multicolumn{3}{|l|}{ Non-behavioural factors } \\
\hline Family history of cystitis & 56 & $28 \%$ \\
\hline Irritable bowel syndrome & 105 & $52 \%$ \\
\hline Constipation & 50 & $25 \%$ \\
\hline Diarrhoea & 27 & $14 \%$ \\
\hline Alternating diarrhoea/constipation & 30 & $15 \%$ \\
\hline Perceived vaginal dryness & 121 & $60 \%$ \\
\hline Non-perceived vaginal dryness & 23 & $12 \%$ \\
\hline
\end{tabular}

Table 2. Risk factors for complications.

\begin{tabular}{|c|c|c|}
\hline Risk Factors for Complications & $\mathbf{N}$ & $\%$ \\
\hline Age $>75$ years & 49 & $24 \%$ \\
\hline Organic abnormalities of the urinary tract & 42 & $22 \%$ \\
\hline Hymenal adhesions & 13 & $7.5 \%$ \\
\hline Urolithiasis & 25 & $13 \%$ \\
\hline Bladder diverticula & 4 & $2 \%$ \\
\hline Dilated urethral stenosis & 20 & $10 \%$ \\
\hline Non-operated pelvic floor dysfunction & 18 & $10 \%$ \\
\hline Sling surgery-Prolapse cure & 49 & $24 \%$ \\
\hline Among which ineffective and/or with complications (34/49) & 34 & $69 \%$ \\
\hline Other urological surgery & 25 & $12 \%$ \\
\hline
\end{tabular}


Table 2. Cont.

\begin{tabular}{|c|c|c|}
\hline Risk Factors for Complications & $\mathbf{N}$ & $\%$ \\
\hline \multicolumn{3}{|l|}{ Functional abnormalities of the urinary tract } \\
\hline Residual urine $>100 \mathrm{~mL}$ & 32 & $16 \%$ \\
\hline Neurogenic bladder & 7 & $3 \%$ \\
\hline Hyperactive bladder & 10 & $6 \%$ \\
\hline Dystonic urethral sphincter & 8 & $5 \%$ \\
\hline Medical treatment favouring post-micturition bladder residue & 48 & $24 \%$ \\
\hline Among which those with proven bladder residue $(8 / 48)$ & 8 & $16 \%$ \\
\hline \multicolumn{3}{|l|}{ Iatrogenic immune depression: } \\
\hline methotrexate (8), steroids (9), immune suppressors (11), immune modulators (1), monoclonal antibodies (7) & 27 & $13 \%$ \\
\hline Non-iatrogenic immune depression: & & \\
\hline amyloidosis, hypogammaglobulinemia, HIV & 3 & $1 \%$ \\
\hline Pelvic radiotherapy & 3 & $1 \%$ \\
\hline
\end{tabular}

A urine culture was prescribed at each episode for $65 \%$ of patients, while this was occasional for $32 \%$. Follow-up urine cultures were performed in $20 \%$ of patients (Table 3 ).

Table 3. Frequency of urine culture and urinalysis.

\begin{tabular}{ccc}
\hline Urine Culture and Urinalysis & $\mathbf{N}$ & $\mathbf{\%}$ \\
\hline Never & 6 & $3 \%$ \\
Sometimes & 65 & $32 \%$ \\
Always & 131 & $65 \%$ \\
Post-treatment urine culture and urinalysis & & \\
Never & 161 & $80 \%$ \\
Sometimes & 17 & $8 \%$ \\
Always & 12 & $12 \%$ \\
\hline
\end{tabular}

Results of urine cultures provided by patients showed that E. coli, Klebsiella spp. and Enterococcus spp. accounted for $88 \%, 28 \%$ and $21 \%$ of cultured samples, respectively. Extended-spectrum beta-lactamase-producing Enterobacteriaceae were identified in 17\% of isolates.

Antimicrobial agents prescribed during an acute episode are shown in Figure 1. Treatment was most often prescribed empirically and rarely readjusted according to urine culture results. Treatment was considered fully effective by $40.5 \%$ of patients, variably effective according to the episode by $53.0 \%$ and ineffective by $6.5 \%$.

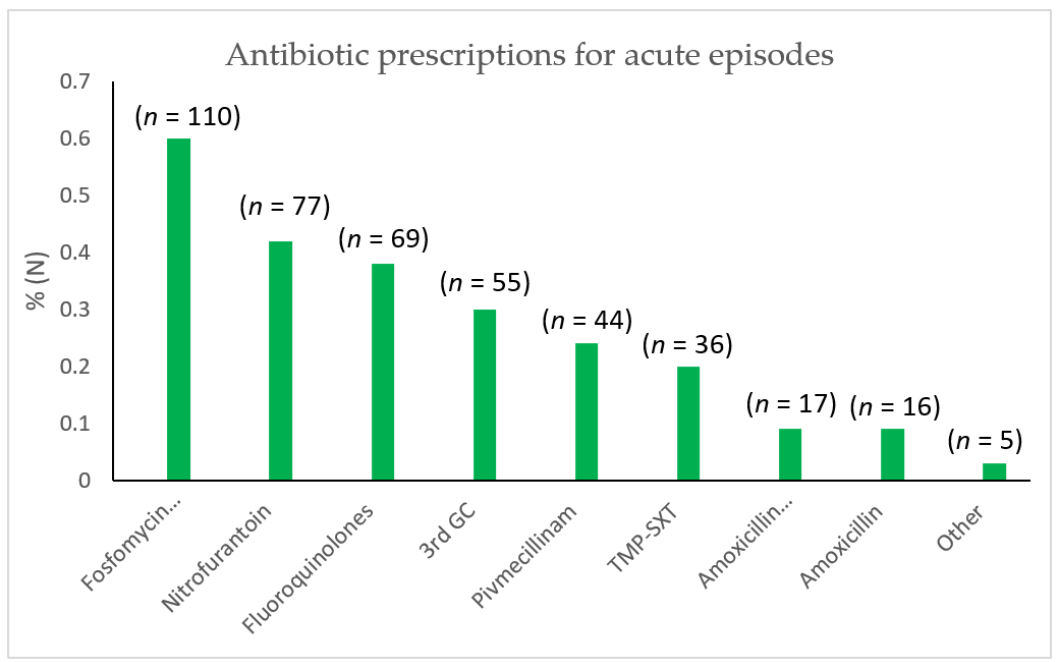

Figure 1. Distribution of prescribed antimicrobial agents (3rd GC: third generation cephalosporins). 
With regard to the recommendations put forward by the French Language Society of Infectious Diseases (SPILF), which states that 3rd generation cephalosporins and quinolones should be avoided in cystitis, antibiotic treatment was appropriate for $18.5 \%$ of patients, variably appropriate according to the episode for $55.0 \%$ and inappropriate for $26.5 \%$ : there were 69 fluoroquinolone prescriptions and 55 3rd generation cephalosporin prescriptions (Figure 1).

Of 90 documented prescriptions for antibiotic prophylaxis, 42\% were appropriate: weekly fosfomycin-trometamol (FT) or weekly co-trimoxazole (TMP-SXT) (Figure 2). Treatment was considered fully effective by $15 \%$ of patients questioned, variably effective by $12 \%$ and ineffective by $57 \%$.

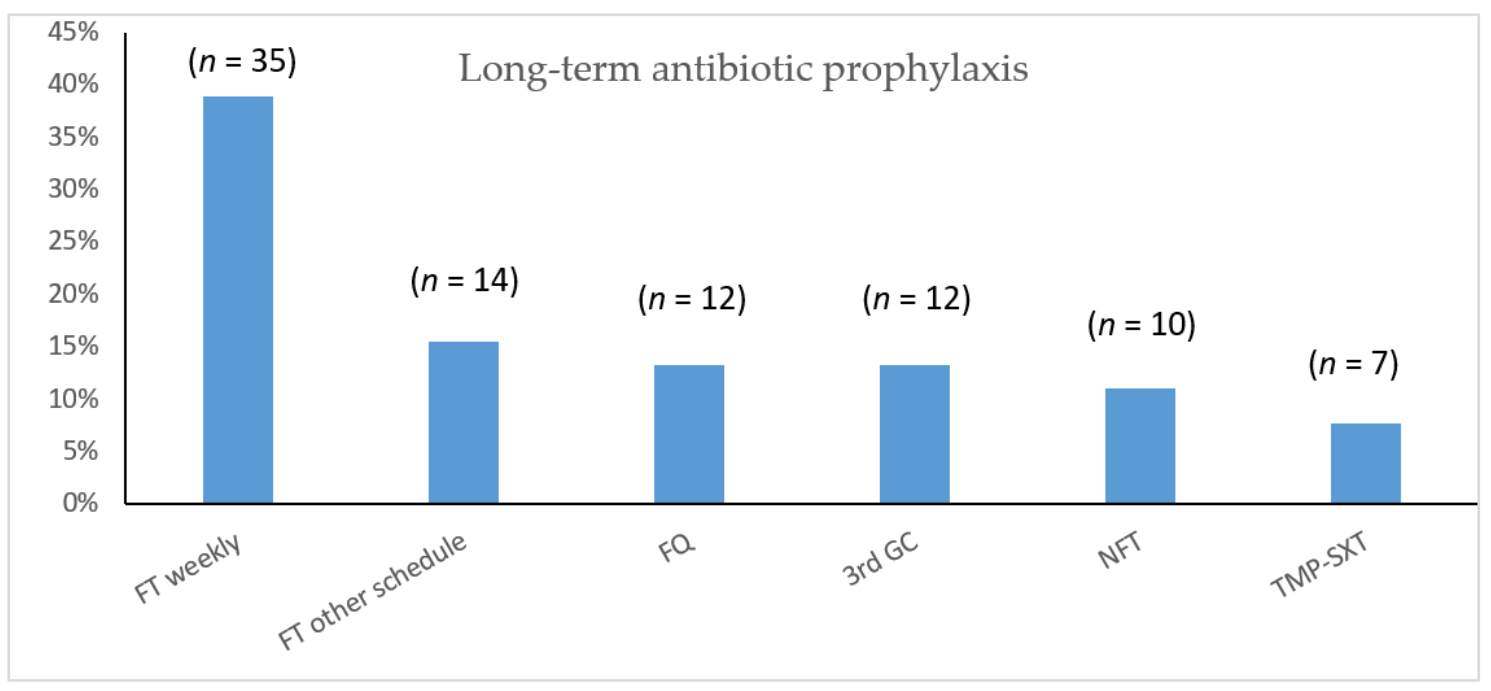

Figure 2. Long-term prophylactic antibiotic prescriptions, FT: Fosfomycin trometamol; FQ: fluoroquinolones; 3rd GC: 3rd generation cephalosporins; NFT: nitrofurantoine; TMP-SXT: trimethoprimsulfamethoxazole.

Prior to seeking infectious diseases specialist advice, $79 \%$ of women had consulted a urologist and $74 \%$ a gynaecologist. Examination of the perineum was not systematic; patients were not always informed of the conclusion. Investigations undergone by patients are shown in Figure 3.

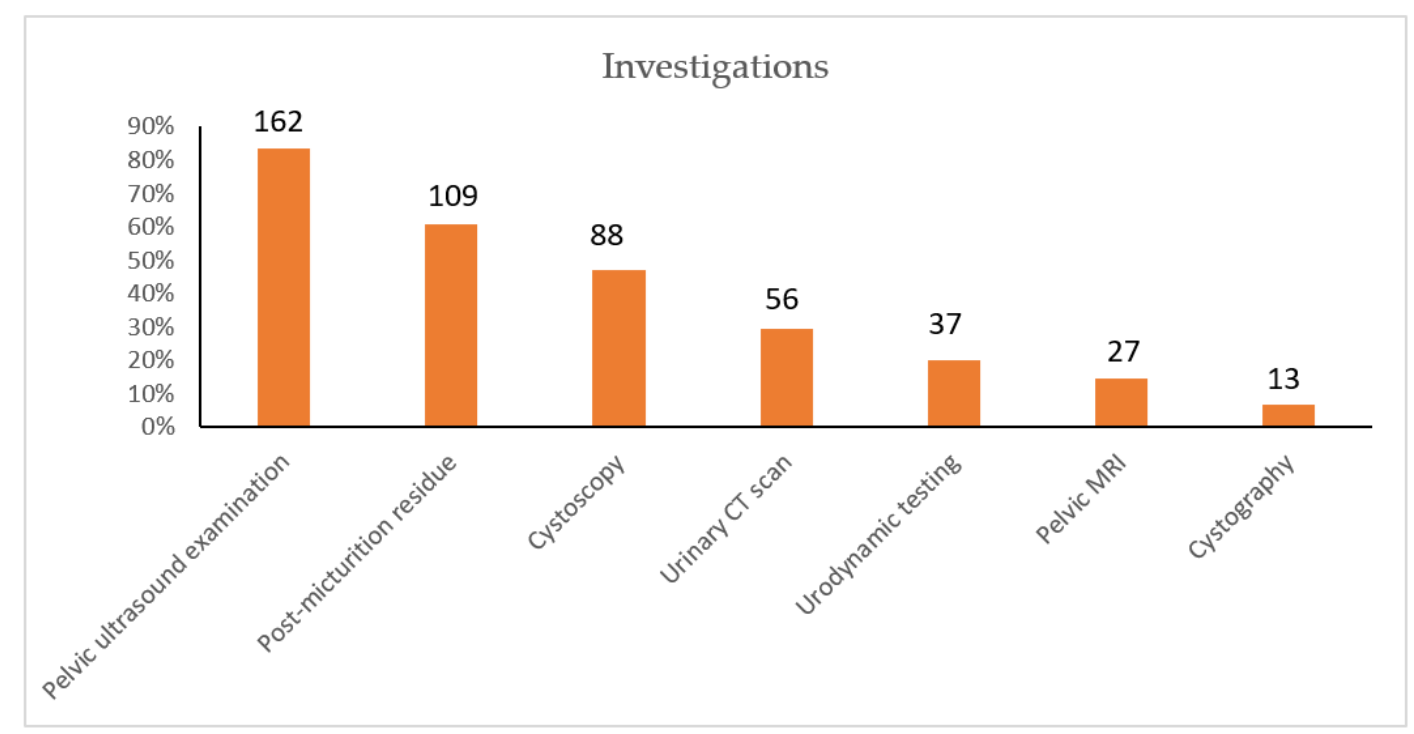

Figure 3. Investigations undergone by patients with recurring cystitis. 
According to the SPILF recommendations, the following investigations were considered inappropriate for the patients considered: cystoscopy $(n=12), \operatorname{MRI}(n=6)$, urology CT scan $(n=8)$, cystography $(n=4)$.

Antibiotic treatment resulted in adverse events in $37 \%$ of patients, consisting in gastrointestinal disturbances, frequent vaginal candidiasis, and cutaneous reactions. Four women presented with fluoroquinolone-related tendinopathy, one with toxidermia and one developed Lyell's syndrome.

Most women (70\%) resorted to non-antibiotic therapies, mainly plant-based compounds and particularly proanthocyanidine (cranberry). Other approaches included homeopathy, D mannose, acupuncture, hypnosis, naturopathy, Chinese medicine, essential oils and mesotherapy. However, their use was highly variable, both in duration and modality (acute episode or background treatment).

Most patients (53\%) were referred to the infectious diseases department by their general practitioner, the remainder by urologists $(24 \%)$, gynaecologists $(8 \%)$, or other specialists $(15 \%)$.

\subsection{Patient Categories}

Based on collected data, the following patient categories were identified (Figure 4)

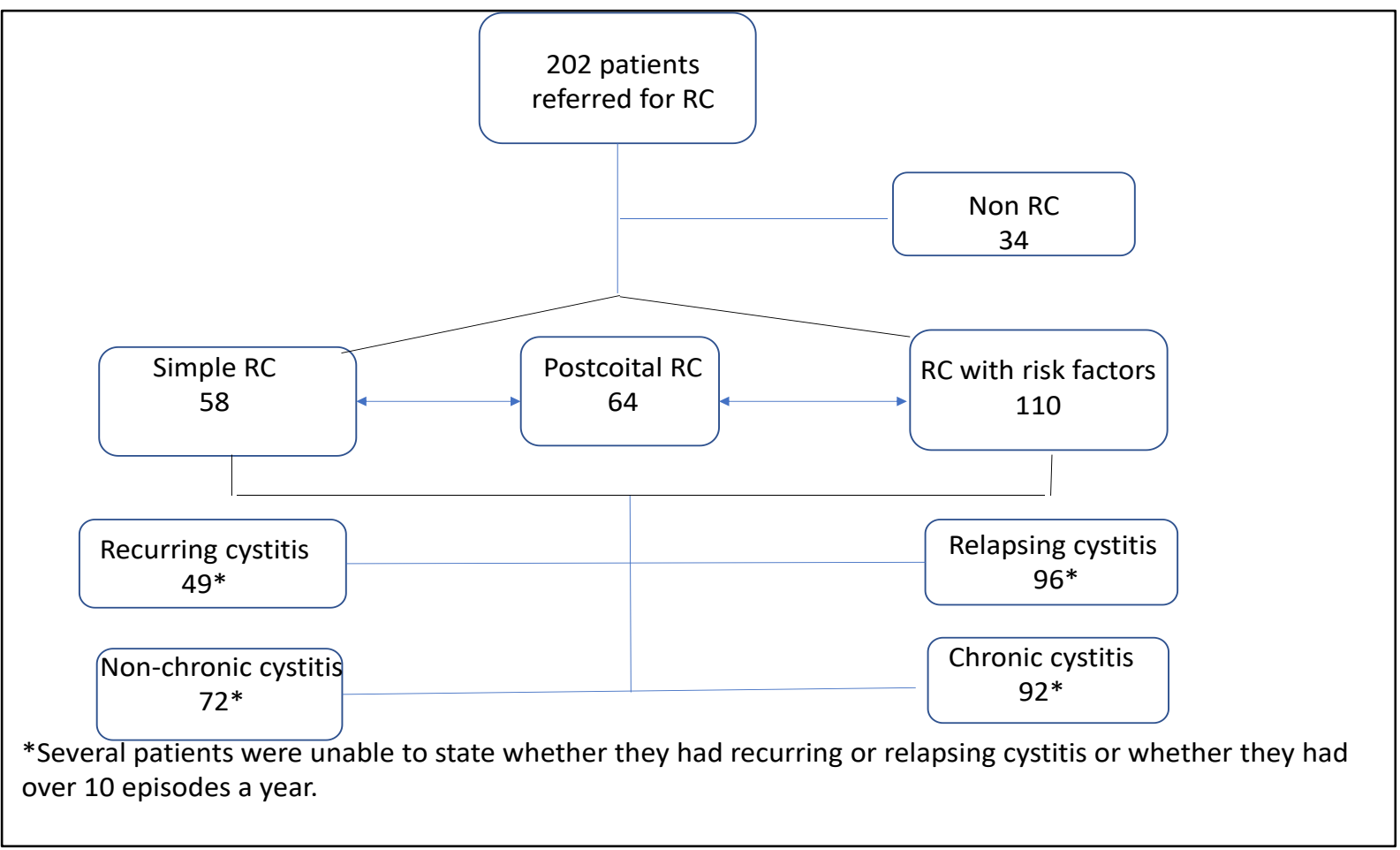

Figure 4. Patient distribution according to RC category.

Simple RC (29\%), RC at risk for complications (54\%), post-coïtal cystitis (32\%), recurring cystitis due to different microbial agents (24\%), relapsing cystitis due to the same microbial agent (48\%), chronic RC (56\%) arbitrarily defined as $>10$ cystitis episodes/year.

There was some overlap between these categories, as $60 \%$ of women at risk of complications had chronic RC and 58\% had relapses. Antibiotic treatment was inappropriate in $85 \%$ of acute cases and $35 \%$ in prophylaxis.

For those women considered as having simple RC, $46.5 \%$ had chronic RC and 55\% had relapses. Antibiotic treatment was inappropriate in $72 \%$ of acute cases and $22 \%$ in prophylaxis. 
Many patients considered to be suffering from chronic RC had relapses. Bacterial documentation was lacking for $11 \%$ of women. For those reporting post-coital RC, the only contributing factor was sexual intercourse in $44 \%$ of cases.

\subsection{Differential and Associated Diagnoses}

Referral to the infectious diseases department led to the conclusion that $17 \%$ of women did not meet criteria for RC but presented with symptoms of urinary colonisation and/or sterile urine culture.

Among those with definite RC, 28\% were found to have an associated diagnosis: painful bladder syndrome (PBS: 19\%), suspected interstitial cystitis (IC: $8 \%$ ) or confirmed by cystoscopy $(3.5 \%)$, urethral syndrome (10.5\%), vulvar/vaginal pain (7\%). Almost half of those with PBS or IC complained of bowel disorders.

\section{Discussion}

The present study collected data from a variety of women with $\mathrm{RC}$, regardless of age and risk factors for complications, including contributing factors, behavioural aspects and psychological impact. A major finding was the chronic state of anxiety revealed by many women and the importance of stress as a trigger factor. These are not considered in recent recommendations [8,9]. Few studies describe such features as contributing factors. However, Reese et al. had already reported, in 1977, that 30\% of women with cystitis had a history of anxiety and/or depression antedating micturition symptoms [13]. Anxious, obsessive personalities with somatic expression of their psychological/emotional disorder may prevail among women with $\mathrm{RC}$, interfering with complete voiding, and the authors suggest that a multifactorial approach, including awareness of psychiatric factors, will reduce treatment failure rate. It has been hypothesized that activation of the autonomous nervous system through stress could result in relaxation of the detrusor muscle and contraction of the smooth muscles of the urethral sphincter, leading to urinary retention and, hence, to RC. Research on the potential benefits of hypnosis is currently ongoing at the Nice University hospital infectious diseases department, an approach supported by the stress and neuroticism observed among patients. Such a broader approach is increasingly favoured, addressing both somatic and psychological aspects of the condition, while improving women's well-being, reducing inappropriate antibiotic use, bacterial resistance and, potentially, costs $[14,15]$. Fan et al. explored the psychological profile of women with urinary dysfunction and found that 59\% were depressed [16]. Other authors suggest that neuroticism, i.e., a tendency to experience negative feelings such as anxiety and guilt, might be more frequent in patients with $\mathrm{RC}$ and influence patients' behaviour as a result of increased sensitivity to their surrounding environment in relation to a particularly reactive sympathetic nervous system [17]. The authors advise taking this trait into consideration to widen the approach to management, which should include both organic and psychological factors. Sexual violence was a delicate subject to bring up, but 2 of the 11 patients questioned admitted having been subjected to it, and, in view of its considerably distressing impact, screening should be extended [18,19]. Indeed, immune dysregulation has been shown among adults who experienced stressful situations during childhood [20].

Over half the patients stated they had at least ten episodes per year, showing the extent of the impact on their professional and personal life. Recent studies have shown that physical discomfort and psychological distress affected women's social and professional activities and intimate life, with $17 \%$ of women renouncing sexual intercourse due to its link with cystitis [21-23]. Confronted with antimicrobial treatment failures and the perceived lack of concern on the part of health professionals, women felt disparaged, and their response was one of resignation [21].

In view of the above-mentioned multi-faceted features of RC, and the shortcomings of routine medical management, most women resorted to non-antibiotic approaches: plant extracts, probiotics, D-mannose and Chinese medicine [24,25]. Proanthocyanidin, a polyphenol extracted from cranberries, has been shown to prevent E. coli from adhering to 
the urethral epithelium, to exert an anti-inflammatory effect and to reduce urine $\mathrm{pH}[26,27]$. Although the effectiveness of such approaches has yet to be clearly demonstrated, avoidance of antimicrobial resistance resulting from iterative antibiotic courses argues in their favour for many patients, providing that prescriptions are appropriate and innocuous [28].

Relapsing E. coli infection was frequent, suggesting permanent colonisation of the bladder by the pathogen in its intracellular and quiescent form, escaping immune response and antimicrobial activity $[29,30]$. Indeed, uropathogenic E. coli possess type 1 pili, allowing them to penetrate the bladder epithelium, a property that can be countered by D-mannose [31,32]. Host genetic characteristics also play a major role in the immune response to infection, namely Toll-like receptor variability [33].

Among our patient cohort, $17 \%$ were carriers of extended-spectrum beta-lactamaseproducing Enterobacteriaceae, i.e., four-fold the average rate in France among women with UTI [34]. Multi-resistant bacteria currently account yearly for 125,000 infections and 5500 deaths in France [35]. Given the proportion of inappropriate prescriptions in our patient cohort, efforts towards improving management of RC appear essential.

Over $50 \%$ of patients were at risk for complications, among whom a quarter were over 75 years of age. In the absence of any specific recommendation for this patient category, these women were particularly exposed to inappropriate antimicrobial treatment.

A history of acute pyelonephritis was reported for $40 \%$ of the cohort, regardless of risk factors for complications. Eto et al. suggest that patients with $\mathrm{RC}$ have a higher risk of developing acute pyelonephritis, although the high proportion observed among our patients may be due to a selection bias, since they had been referred to an infectious disease specialist [29].

Some of the risk factors for RC mentioned by patients could be corrected: excessive intimate hygiene disrupting the protective lipid barrier, insufficient hydration, consumption of irritants, retained micturition or voiding in a non-sitting posture. Most complained of intestinal disorders, (diarrhoea was stated as a trigger factor more often than constipation), vaginal dryness and pelvic floor dysfunction. Post-coital RC was mentioned regardless of age. Most patients had undergone menopause. According to international studies, over 50\% of women suffer from genitourinary syndrome of menopause (GSM), i.e., atrophic vaginitis and increased vaginal $\mathrm{pH}$ related to oestrogen deprivation, with genital, urological and sexual symptoms that patients are reluctant or embarrassed to discuss, when appropriate management would improve quality of life and prevent complications, including urinary urgency and incontinence [36,37].

Two thirds of women who had undergone sling surgery for urinary incontinence or prolapse reported complications, considering that the procedure had triggered the onset of RC. Concern over the innocuity of these procedures has led to current monitoring of subsequent complications [38].

Lastly, a number of women reported chronic pelvic pain, i.e., painful bladder syndrome, interstitial cystitis, urethral syndrome and/or chronic vulvodynia in association with $R C$, for which a specific aetiology is rarely identified, and which can benefit from a patient-centred approach, taking the psychological component into account. A smartphone application has been developed for these women and a similar one dedicated to RC might prove useful [39].

Although current recommendations state that infectious disease specialist advice should be sought for women, patients in the present study were often referred several years after their first episodes of RC. In the present study, the diagnosis was unfounded in $17 \%$ of women. Aside from typical clinical signs, the questionnaire investigated the presence of "cloudy" or "smelly" urine, neither of which necessarily point to a UTI, providing the opportunity to inform patients of true symptoms of infection.

Many women were prescribed a fosfomycin-trometamol combination. However, fluoroquinolones and 3GC were prescribed to $38 \%$ and $30 \%$ of patients during an acute episode, respectively. Urine dipstick tests were rarely performed in this cohort, and urinalysis was prescribed to most women, according to recommendations, and repeated following antimi- 
crobial treatment for at least $20 \%$ of them, which is not recommended, as this could lead to prescription of a second-line antibiotic in the case of persistent bacteriuria, regardless of symptomatology. Indeed, urinary bacterial colonisation still leads to numerous unnecessary antibiotic prescriptions. Antimicrobial prophylaxis, which included fluoroquinolones (6\% of patients) and 3GC (6\% of patients), was not consistently appropriate and was judged unsatisfactory by a majority of women, with $37 \%$ reporting adverse events.

Among our patients, many had unnecessarily undergone a cystoscopy, which was not recommended in their case. Furthermore, urologists had not given patients the results of the procedure. The SPILF recommendations state that, for women with recurrent cystitis who are not at risk for complications, investigations should be limited to clinical pelvic and ultrasound examination. In the case of risk factors for complications, investigations should be decided according to the clinical situation.

Thus, there is a broad scope for improving the management of RC. Systematic screening and consideration of all these factors would assist the physician in determining a specific and coherent management strategy thanks to a decision-making algorithm that would include both somatic and psychological/behavioural characteristics while complying with good clinical practice recommendations. This should involve a dedicated medical consultation and identification of expert referees, while empowering and educating women to achieve self-care, based on their needs and expectations. Anticipatory prescriptions for urinalysis, provision of clear guidelines in case of cystitis, and education on self-treatment would contribute to achieve this. An information leaflet has, thus, been developed to provide patients with better knowledge of their condition and more autonomy to manage it.

This study has several limitations. A recall bias was likely, as some women had a protracted history of RC and could not always remember the antibiotic compounds or investigations they had been prescribed. Not all could provide informative documentation. Furthermore, women who presented at the infectious diseases outpatient department were often referred by urologists who were aware of issues related to RC, potentially also resulting in a selection bias.

The present study points out the current failings in the management of RC. It reveals excessive, unnecessary antibiotic prescriptions, including critically important compounds, resulting in over a three-fold increase in multi-drug-resistant E. coli, compared to the rate of $4.5 \%$ in community samples in France [40], a lack of treatment re-assessment based on urine culture results following an initial empirical prescription, and superfluous post-treatment urine cultures, increasing the financial burden of the condition.

The issue addressed in our manuscript does not appear restricted to France: a survey conducted in England among patients and GPs showed that (1) management of recurrent cystitis was often unsatisfactory for women due to their lack of communication with their GP, (2) antibiotic stewardship could be improved and (3) patient empowerment was desirable for self-management of their condition [7]. Similarly, a study conducted in five countries highlighted the impact of RC on women's quality of life [12]. In Canada, recent efforts have resulted in better characterization of patients and in improved antibiotic stewardship with fewer and more appropriate prescriptions, although ciprofloxacin remains the second most prescribed antibiotic for RC [41]. Furthermore, among patients who visited the ID department, some came from various regions of France, but also from Spain or Italy, expressing similar complaints.

The state of stress and anxiety related to recurrent cystitis, whether as its cause or its consequence, the pain accompanying each episode and the resulting disruption of daily life are usually underestimated by health professionals as well as by society. Women resort to various alternative treatments in an attempt to manage their condition, while avoiding iterative antibiotic courses that they increasingly resent. While treatment of cystitis is relatively simple and straightforward, the aim should be to treat RC using an approach that is as respectful as possible of the microbial ecosystem through appropriate antibiotic stewardship while avoiding secondary infection, i.e., to solve the problem as best 
as possible with the least risk. At the same time, this approach must take into account that women currently have to wait 5 to 7 days from the time they take their urine sample to the lab, obtain the result, and see their GP to get a prescription, a complex and lengthy process during which their pain and discomfort significantly impair their quality of life. This could be shortened if they were given more autonomy, advice and means of self-care. Furthermore, in view of the range of patient categories, it is important to consider the highly multifactorial aspect of cystitis that should, thus, require a tailored and holistic approach, based on relevant recommendations, taking into account its psychological aspects as well as the microbial ecosystem.

Such an autonomous, ecological approach should be encouraged by providing appropriate advice and adequate, caring and empathic support on the part of their care-providers.

Supplementary Materials: The following supporting information can be downloaded at: https: / / www.mdpi.com/article/10.3390/antibiotics11020269/s1, File S1: Patient questionnaire.

Author Contributions: Conceptualization, V.M.; methodology, V.M.; software, S.B.H.M.; validation, V.M.; formal analysis, S.B.H.M.; investigation, S.B.H.M. and E.D.; resources, V.M. and E.D.; writingoriginal draft preparation, S.B.H.M.; writing-review and editing, V.M.; supervision, V.M. All authors have read and agreed to the published version of the manuscript.

Funding: This research received no external funding.

Institutional Review Board Statement: The study was conducted in accordance with the Declaration of Helsinki and approved by the Institutional Review Board of the Centre Hospitalo-universitaire de Nice, France.

Informed Consent Statement: Ethical approval was not required for this study, as it was an internal single-centre institutional research project in line with the general information provided to all patients on data utilisation. A standard institutional document explaining this use is systematically signed by patients visiting the institution. The study has been entered in the institutional register of data processing activity under number 2022033CHUN.

Data Availability Statement: The data presented in this study are available on request from the corresponding author.

Conflicts of Interest: The authors declare no conflict of interest.

\section{References}

1. ANSM-La Consommation d'antibiotiques en France en 2016-Décembre 2017. Available online: https://www.anses.fr/fr/ content/surveillance-de-lusage-en-france. (accessed on 25 December 2021).

2. François, M.; Hanslik, T.; Dervaux, B.; Le Strat, Y.; Souty, C.; Vaux, S.; Maugat, S.; Rondet, C.; Sarazin, M.; Heym, B.; et al. The economic burden of urinary tract infections in women visiting general practices in France: A cross-sectional survey. BMC Health Serv. Res. 2016, 16, 365. [CrossRef] [PubMed]

3. Lai, J.; Setodji, C.M.; Clemens, J.Q. Urologic Diseases of America Project. Incidence and Management of Uncomplicated Recurrent Urinary Tract Infections in a National Sample of Women in the United States. Urology 2016, 90, 50-55. [CrossRef] [PubMed]

4. Haab, F.; Costa, P.; Colau, J.C.; Gérard, A.; Liard, F.; Bohbot, J.M.; Leng, J.J.; Lobel, B.; Soussy, C.J.; Boulanger, P. Management of urinary tract infections in women. Epidemiologic survey of 7916 women in general practice. Presse Med. 2006, 35 Pt 1, 1235-1240. [CrossRef]

5. Haslund, J.M.; Dinesen, M.R.; Nielsen, A.B.S.; Llor, C.; Bjerrum, L. Different recommendations for empiric first-choice antibiotic treatment of uncomplicated urinary tract infections in Europe. Scand. J. Prim. Health Care 2013, 31, 235-240. [CrossRef] [PubMed]

6. Armelle, J. Cystites récidivantes: Des moyens de prévention non médicamenteux. Progrès Urol. 2017, 27, 823-830. [CrossRef]

7. Lecky, D.M.; Howdle, J.; Butler, C.C.; McNulty, C.A. Optimising management of UTIs in primary care: A qualitative study of patient and GP perspectives to inform the development of an evidence-based, shared decision-making resource. Br. J. Gen. Pract. 2020, 70, e330-e338. [CrossRef]

8. Available online: https://www.infectiologie.com/UserFiles/File/spilf/recos/infections-urinaires-spilf.pdf (accessed on 25 December 2021).

9. Caron, F.; Galperine, T.; Flateau, C.; Azria, R.; Bonacorsi, S.; Bruyère, F.; Cariou, G.; Clouqueur, E.; Cohen, R.; Doco-Lecompte, T.; et al. Practice guidelines for the management of adult community-acquired urinary tract infections. Med. Mal. Infect. 2018, 48, 327-358. [CrossRef]

10. Available online: https://www.sciencedirect.com/science/article/pii/S0399077X18304463 (accessed on 25 December 2021). 
11. Holm, S.E.; Stenlund, H.; Lundholm, R.; Monsen, T.J. The natural course of uncomplicated lower urinary tract infection in women illustrated by a randomized placebo-controlled study. Scand. J. Infect. Dis. 2004, 36, 296-301.

12. Wagenlehner, F.; Wullt, B.; Ballarini, S.; Zingg, D.; Naber, K.G. Social and economic burden of recurrent urinary tract infections and quality of life: A patient web-based study (GESPRIT). Expert Rev. Pharm. Outcomes Res. 2018, 18, 107-117. [CrossRef]

13. Rees, D.L.; Farhoumand, N. Psychiatric aspects of recurrent cystitis in women. Br. J. Urol. 1977, 49, 651-658. [CrossRef]

14. Available online: https://www.cairn.info/revue-hegel-2021-4-page-332.htm (accessed on 25 December 2021).

15. Available online: https://www.youtube.com/watch?v=Cjn1e8A1F6E (accessed on 25 December 2021).

16. Fan, Y.H.; Lin, A.T.; Wu, H.M.; Hong, C.J.; Chen, K.K. Psychological profile of female patients with dysfunctional voiding. Urology 2008, 71, 625-629. [CrossRef] [PubMed]

17. Hunt, J.C.; Waller, G. Psychological factors in recurrent uncomplicated urinary tract infection. Br. J. Urol. 1992, 69, 460-464. [CrossRef] [PubMed]

18. Sigurdardottir, S.; Halldorsdottir, S. Screaming Body and Silent Healthcare Providers: A Case Study with a Childhood Sexual Abuse Survivor. Int. J. Environ. Res. Public Health 2018, 15, 94. [CrossRef] [PubMed]

19. Panicker, J.N.; Anding, R.; Arlandis, S.; Blok, B.; Dorrepaal, C.; Harding, C.; Marcelissen, T.; Rademakers, K.; Abrams, P.; Apostolidis, A. Do we understand voiding dysfunction in women? Current understanding and future perspectives: ICI-RS 2017. Neurourol. Urodyn. 2018, 37, S75-S85. [CrossRef]

20. Fagundes, C.P.; Glaser, R.; Kiecolt-Glaser, J.K. Stressful early life experiences and immune dysregulation across the lifespan. Brain Behav. Immun. 2013, 27, 8-12. [CrossRef]

21. Bermingham, S.L.; Ashe, J.F. Systematic review of the impact of urinary tract infections on health-related quality of life. BJU Int. 2012, 110, E830-6. [CrossRef] [PubMed]

22. Flower, A.; Bishop, F.L.; Lewith, G. How women manage recurrent urinary tract infections: An analysis of postings on a popular web forum. BMC Fam. Pract. 2014, 15, 162. [CrossRef]

23. Ciani, O.; Grassi, D.; Tarricone, R. An economic perspective on urinary tract infection: The "costs of resignation". Clin. Drug Investig. 2013, 33, 255-261. [CrossRef]

24. Salinas-Casado, J.; Méndez-Rubio, S.; Esteban-Fuertes, M.; Gómez-Rodríguez, A.; Vírseda-Chamorro, M.; Luján-Galán, M.; Rituman, G. Efficacy and safety of D-mannose ( $2 \mathrm{~g}), 24 \mathrm{~h}$ prolonged release, associated with Proanthocyanidin (PAC), versus isolate PAC, in the management of a series of women with recurrent urinary infections. Arch. Esp. Urol. 2018, 71, 169-177.

25. Flower, A.; Wang, L.-Q.; Lewith, G.; Liu, J.P.; Li, Q. Chinese herbal medicine for treating recurrent urinary tract infections in women. Cochrane Database Syst. Rev. 2015, 6, CD010446. [CrossRef]

26. Fu, Z.; Liska, D.; Talan, D.; Chung, M. Cranberry Reduces the Risk of Urinary Tract Infection Recurrence in Otherwise Healthy Women: A Systematic Review and Meta-Analysis. J. Nutr. 2017, 147, 2282-2288. [CrossRef] [PubMed]

27. Aune, A.; Alraek, T.; LiHua, H.; Baerheim, A. Acupuncture in the Prophylaxis of Recurrent Lower Urinary Tract Infection in Adult Women. Scand. J. Prim. Health Care 1998, 16, 37-39. [CrossRef]

28. Sihra, N.; Goodman, A.; Zakri, R.; Sahai, A.; Malde, S. Nonantibiotic prevention and management of recurrent urinary tract infection. Nat. Rev. Urol. 2018, 15, 750-776. [CrossRef] [PubMed]

29. Eto, D.S.; Sundsbak, J.L.; Mulvey, M.A. Actin-gated intracellular growth and resurgence of uropathogenic Escherichia coli. Cell. Microbiol. 2006, 8, 704-717. [CrossRef]

30. Scott, V.C.; Haake, D.A.; Churchill, B.M.; Justice, S.S.; Kim, J.H. Intracellular Bacterial Communities: A Potential Etiology for Chronic Lower Urinary Tract Symptoms. Urology 2015, 86, 425-431. [CrossRef] [PubMed]

31. Wellens, A.; Garofalo, C.; Nguyen, H.; Van Gerven, N.; Slättegård, R.; Hernalsteens, J.P.; Wyns, L.; Oscarson, S.; De Greve, H.; Hultgren, S.; et al. Intervening with urinary tract infections using anti-adhesives based on the crystal structure of the FimH-oligomannose-3 complex. PLoS ONE 2008, 3, e2040. [CrossRef]

32. Hawn, T.R.; Scholes, D.; Li, S.S.; Wang, H.; Yang, Y.; Roberts, P.L.; Stapleton, A.E.; Janer, M.; Aderem, A.; Stamm, W.E.; et al Toll-like receptor polymorphisms and susceptibility to urinary tract infections in adult women. PLoS ONE 2009, 4, e5990. [CrossRef]

33. Martin, D.; Fougnot, S.; Grobost, F.; Thibaut-Jovelin, S.; Ballereau, F.; Gueudet, T.; de Mouy, D.; Robert, J. ONERBA-ville network. Prevalence of extended-spectrum beta-lactamase producing Escherichia coli in community-onset urinary tract infections in France in 2013. J. Infect. 2016, 72, 201-206. [CrossRef]

34. Cassini, A.; Högberg, L.D.; Plachouras, D.; Quattrocchi, A.; Hoxha, A.; Simonsen, G.S.; Colomb-Cotinat, M.; Kretzschmar, M.E.; Devleesschauwer, B.; Cecchini, M.; et al. Burden of AMR Collaborative Group Attributable Deaths and Disability-Adjusted Life-Years Caused by Infections with Antibiotic-Resistant Bacteria in the EU and the European Economic Area in 2015: A Population-Level Modelling Analysis. Lancet Infect. Dis. 2019, 19, 56-66. [CrossRef]

35. Matthews, S.J.; Lancaster, J.W. Urinary tract infections in the elderly population. Am. J. Geriatr. Pharmacother. 2011, 9, 286-309. [CrossRef]

36. Gandhi, J.; Chen, A.; Dagur, G.; Suh, Y.; Smith, N.; Cali, B.; Khan, S.A. Genitourinary syndrome of menopause: An overview of clinical manifestations, pathophysiology, etiology, evaluation, and management. Am. J. Obstet. Gynecol. 2016, $215,704-711$. [CrossRef] [PubMed] 
37. Portman, D.J.; Gass, M.L. Vulvovaginal Atrophy Terminology Consensus Conference Panel. Genitourinary syndrome of menopause: New terminology for vulvovaginal atrophy from the International Society for the Study of Women's Sexual Health and the North American Menopause Society. Menopause 2014, 79, 349-354.

38. Fritel, X.; Campagne-Loiseau, S.; Cosson, M.; Ferry, P.; Saussine, C.; Lucot, J.P.; Salet-Lizee, D.; Barussaud, M.L.; Boisramé, T.; Carlier-Guérin, C.; et al. Complications after pelvic floor repair surgery (with and without mesh): Short-term incidence after 1873 inclusions in the French VIGI-MESH registry. BJOG 2020, 127, 88-97. [CrossRef] [PubMed]

39. Griffith, J. Designing a Mobile Health Application Prototype for the Management of Interstitial Cystitis/Painful Bladder Syndrome. Stud. Health Technol. Inform. 2017, 245, 94-97.

40. Available online: https:// medqualville.antibioresistance.fr/resistances / synthese?accommodation=VILLE\&age=all\&analyze type1=S\&analyze_type2=S\&antibiotic1\&antibiotic2\&bacterium_code=Ecoli\&departement\&level=reseau\&phenotype=all\& region\&sample_type=URINES\&sex=all\&year=2021\#year-detail (accessed on 25 December 2021).

41. Hickling, D.R. Recurrent urinary tract infection: Rates and prescription patterns in the antibiotic stewardship era. Can. Urol. Assoc. J. 2021, 15, 405-406. [CrossRef] 